\title{
Sex Differences Associated with Primary Biliary Cirrhosis
}

\author{
Daniel S. Smyk, ${ }^{1}$ Eirini I. Rigopoulou, ${ }^{2}$ Albert Pares, ${ }^{3}$ \\ Charalambos Billinis, ${ }^{4}$ Andrew K. Burroughs, ${ }^{5}$ Luigi Muratori, ${ }^{6}$ \\ Pietro Invernizzi, ${ }^{7,8}$ and Dimitrios P. Bogdanos ${ }^{1,2,9}$ \\ ${ }^{1}$ Institute of Liver Studies, King's College London School of Medicine, Denmark Hill Campus, \\ London SE59PJ, UK \\ ${ }^{2}$ Department of Medicine, University of Thessaly Medical School, Viopolis, 41110 Larissa, Greece \\ ${ }^{3}$ Liver Unit, CIBEREHD, IDIBAPS, Hospital Clinic University of Barcelona, 08036 Barcelona, Spain \\ ${ }^{4}$ Department of Microbiology and Parasitology, Faculty of Veterinary Medicine, University of Thessaly, 43100 Karditsa, Greece \\ ${ }^{5}$ The Sheila Sherlock Liver Centre, and University Department of Surgery, Royal Free Hospital, London NW32QG, UK \\ ${ }^{6}$ Department of Clinical Medicine, Alma Mater Studiorum, Università di Bologna, Policlinico Sant'Orsola-Malpighi, \\ 40138 Bologna, Italy \\ ${ }^{7}$ Center for Autoimmune Liver Diseases, Division of Internal Medicine, IRCCS Istituto Clinico Humanitas, 20089 Rozzano, Italy \\ ${ }^{8}$ Division of Rheumatology, Allergy and Clinical Immunology, University of California at Davis, Davis, CA 95616, USA \\ ${ }^{9}$ Department of Cellular Immunotherapy and Molecular Immunodiagnostics, Institute for Biomedical Research \& Technology, \\ 41222 Larissa, Greece
}

Correspondence should be addressed to Dimitrios P. Bogdanos, dimitrios.bogdanos@kcl.ac.uk

Received 27 January 2012; Accepted 27 February 2012

Academic Editor: T. Nakayama

Copyright () 2012 Daniel S. Smyk et al. This is an open access article distributed under the Creative Commons Attribution License, which permits unrestricted use, distribution, and reproduction in any medium, provided the original work is properly cited.

Primary biliary cirrhosis (PBC) is a cholestatic liver disease of autoimmune origin, characterised by the destruction of small intrahepatic bile ducts. The disease has an unpredictable clinical course but may progress to fibrosis and cirrhosis. The diagnostic hallmark of $\mathrm{PBC}$ is the presence of disease-specific antimitochondrial antibodies (AMA), which are pathognomonic for the development of PBC. The disease overwhelmingly affects females, with some cases of male PBC being reported. The reasons underlying the low incidence of males with PBC are largely unknown. Epidemiological studies estimate that approximately 7-11\% of $\mathrm{PBC}$ patients are males. There does not appear to be any histological, serological, or biochemical differences between male and female PBC, although the symptomatology may differ, with males being at higher risk of life-threatening complications such as gastrointestinal bleeding and hepatoma. Studies on X chromosome and sex hormones are of interest when studying the low preponderance of $\mathrm{PBC}$ in males; however, these studies are far from conclusive. This paper will critically analyze the literature surrounding $\mathrm{PBC}$ in males.

\section{Introduction}

Primary biliary cirrhosis $(\mathrm{PBC})$ is a chronic cholestatic liver disease characterised by an immunomediated inflammatory destruction of the small intrahepatic bile ducts, with fibrosis progressing to cirrhosis and subsequent liver failure [1-3]. The disease predominantly affects women ( $90 \%$ of patients) in middle age [1-4]. Studies from the United Kingdom suggest that $\mathrm{PBC}$ is the most frequent autoimmune liver disease, followed by autoimmune hepatitis and primary sclerosing cholangitis [5]. The incidence and prevalence of $\mathrm{PBC}$ appear to be rising in several countries [5-7]. Differences in the clinical course of the disease have been noted between Caucasian, African American, and Hispanic patients in the USA, with cirrhosis presenting more frequently in nonCaucasian patients [8]. Migration studies indicate that an individual's risk for $\mathrm{PBC}$ changes to be in accordance with the local population into which they move. This has led to the appreciation that environmental factors play an important role in the development of the disease $[6,9,10]$.

Patients with $\mathrm{PBC}$ can be either asymptomatic with normal biochemistry tests or asymptomatic with abnormal 



FIGURE 1: Histological staging in a representative case of a patient with primary biliary. Stage 1 reveals duct-centred inflammation showing chronic nonsuppurative destructive cholangitis (black arrows). A tiny granuloma is also seen (grey arrow). Stage 2 shows portal enlargement (arrows) with bile ductular reaction and inflammatory cell infiltration. Stage 3 is characterized by fibrous scaring bridging portal tracts with occasional foci of bile duct loss (no bile duct identified around an artery indicated by arrow). Stage 4 shows cirrhotic transformation.

biochemical blood tests, symptomatic, or finally can have advanced liver disease at the time of diagnosis [1-3]. Patients usually present in early stages, and the diagnosis of $\mathrm{PBC}$ is most often made when the patient is still asymptomatic with an abnormal cholestatic liver biochemistry and an immunological profile compatible with the disease which is discovered at a routine check [1-3]. Presenting symptoms frequently include fatigue, pruritus, and osteoporosis may be observed initially, in the absence of other signs of liver disease $[1-3,11-13]$. The progression of $\mathrm{PBC}$ is usually slow paced, but symptoms of portal hypertension and hepatic decompensation (jaundice, ascites, or variceal bleeding) can develop several years after the initial diagnosis $[1-3]$. The current medical treatment of choice is with ursodeoxycholic acid, which appears to slow the disease progression and greatly improves the quality of life for many patients [14].

The diagnosis of $\mathrm{PBC}$ is based on three widely accepted criteria: biochemical signs of cholestasis, seropositivity for disease-specific autoantibodies, and disease-characteristic histological features (Figure 1) [1-3]. PBC-characteristic histological features include destruction of biliary epithelial cells (BECs) and loss of small bile ducts with portal inflammatory cell infiltration and granuloma formation on occasion [13]. Cholestatic markers include increased levels of alkaline phosphatase (ALP) and gamma-glutamyl transferase ( $\gamma \mathrm{GT})$. IgM may be raised, and the most prominent immunological feature of the disease is the presence of high-titre antibodies against mitochondrial (AMA) and nuclear (ANA) antigens [1-3, 15-24]. AMAs do not appear to have clinical significance; however, disease-specific ANA can identify a subgroup of $\mathrm{PBC}$ patients with more advanced disease $[15,16,24-36]$. The presence of ANA at diagnosis seems to be able to identify individuals who will develop advanced disease faster than those seronegative for these autoantibodies [37]. It should be noted that patients may initially be found to be seronegative for AMA or disease-specific ANA with conventional techniques such as that of indirect immunofluorescence (IFL) [20, 38-40]. More sensitive tests using as antigenic source hybrids containing the major mitochondrial antigens have led to the appreciation that "true" AMA-seronegative cases may exist but are fewer than those considered in the past when conventional AMA testing was based on IFL and enzyme immunoassays based on the M2 antigen [20,38-40].

$\mathrm{PBC}$-specific AMAs are directed against components of the 2-oxo-acid dehydrogenase complexes, especially the E2 subunits of the pyruvate dehydrogenase complex (PDCE2), branched-chain 2-oxoacid dehydrogenase complex (BCOADC), and 2-oxoglutarate dehydrogenase complex (OGDC) $[1,15,16,20,36]$. Anti-PDC-E2 AMAs are present in over $90 \%$ of AMA-positive cases $[1,15]$. Isotypes of AMA may be $\operatorname{IgG}$, IgA, and $\operatorname{IgM}$, but high-titre AMAs of class IgG are found in up to $95 \%$ of patients $[1,15]$. It has been demonstrated that the presence of AMA in the general population is much higher than the prevalence of 
TABLE 1: Features of primary biliary cirrhosis (PBC) in men and women. Although PBC in men and women is largely similar, certain clinical features such as symptomatology and concomitant diseases differ between the sexes. Very little difference is noted in regards to histological or biochemical features, as well as antimitochondrial antibody (AMA) reactivity.

\begin{tabular}{ll}
\hline Feature & Comment \\
\hline Age & (i) Men older than women \\
\hline Histopathology & (i) Largely no difference observed \\
& $\begin{array}{l}\text { (ii) More stage I in women than in men in one study } \\
\text { (iii) One study notes more piecemeal necrosis and pseudoxanthomatous transformation } \\
\text { in symptomatic females, and more stainable copper storage in symptomatic males }\end{array}$ \\
Symptomatology & $\begin{array}{l}\text { (i) Abdominal pain, constitutional symptoms, and pruritus as a single symptom more } \\
\text { common in females } \\
\text { (ii) Jaundice as a single symptom more common in males }\end{array}$ \\
\hline Biochemistry & $\begin{array}{l}\text { (i) Slightly increased ALP in males versus females in one study; higher } \gamma \text {-GT and ALT in } \\
\text { men than in women in another }\end{array}$ \\
\hline Concomitant autoimmune or other diseases & $\begin{array}{l}\text { (i) More females experienced Sicca symptoms, scleroderma, and Raynauds } \\
\text { (ii) Increased incidence of hepatoma in males }\end{array}$ \\
\hline AMA reactivity & (i) Similar antigenic reactivity patterns in males and females among studies \\
\hline ANA reactivity & (i) Anticentromere antibodies more prevalent in women than in men in one study \\
\hline
\end{tabular}

$\mathrm{PBC}$, indicating that AMA may precede the symptomatic onset of the disease [41], and studies have demonstrated that AMA-positive, asymptomatic patients often have histological features diagnostic of, or compatible with, PBC [41-44]. It is therefore considered that seropositivity for AMA is highly predictive of the development of $\mathrm{PBC}$, which indicates the necessity for autoantibody screening and monitoring at regular intervals of close relatives of $\mathrm{PBC}$ patients and females in particular $[36,45]$. However, the mechanisms responsible for the induction of $\mathrm{PBC}$-specific AMAs and ANAs are not well defined [15, 46-51].

As mentioned, disease-specific ANA may have prognostic significance, which has raised the question as to whether diagnostic testing needs to incorporate assays for PBCspecific ANA [36]. Two ANA patterns may be observed on IFL: the "multiple nuclear dot" pattern mainly targets the nuclear body sp100 and promyelocytic leukaemia (PML) proteins and those giving the "nuclear membrane" (rim-like membranous) recognising gp210, nup62 and other nuclear membrane proteins $[16-18,36]$. Both ANA types are present in $30 \%$ of $\mathrm{PBC}$ patients and can be present in AMA-positive and AMA-negative asymptomatic individuals and also in family members of $\mathrm{PBC}$ patients [16-18].

Genetic, epigenetic, environmental, and infectious factors have been considered important for the development of PBC and/or its progression from early stages to more advanced, life-threatening biliary epithelial cell destruction $[33,39,47,48,53-73]$. T cell dysregulation also appears to be a feature of PBC [74-79]. Molecular mimicry and immunological cross-reactivity involving homologous microbial and self-antigens have been considered as mechanisms responsible for the induction of disease-specific autoreactivity [33, $36,50,51,58,59,80-93]$. Genetic and environmental factors are likely involved, as indicated in twin and familial studies [53, 94-97]. Genome-wide association studies (GWASs) have allowed for the identification of genetic associations for $\mathrm{PBC}[39,66,67,98-102]$. In vitro studies have implicated antigen-specific B-, CD4, CD8 T-lymphocyte responses in the induction and/or maintenance of autoaggressive pathology $[44,47,48,61,88,89,103]$.

Both the innate and the adaptive arms of the immune system have been considered important for the loss of immunological tolerance to AMA-specific PDC-E2 targets and the subsequent development of the disease [104-112]. As AMAs appear long before disease onset, investigators thought that antibody-dependent cellular cytotoxicity or antibody-antigen complement activation cell lysis mechanisms may lead to cholangiopathy. The ability of AMAs to inhibit the catalytic activity of PDC-E2 in vitro has further supported the pathophysiological role of AMAs [113]. PDCE2 complexed with anti-PDC-E2 antibodies generate PDCE2-specific cytotoxic cells, at a 100-fold lower concentration compared to the PDC-E2 alone [108, 109]. More recent studies have demonstrated the presence of immunologically intact PDC-E2 and other PBC-specific antigens in the surface of human intrahepatic biliary epithelial cell apoptotic bodies, making these antigens susceptible to antibody recognition, a feature which may also promote autoaggression [110-112]. The contribution of the innate and adaptive immune response in the development of $\mathrm{PBC}$ has been indicated in animal models resembling human $\mathrm{PBC}$-specific immunopathology $[47,63,65]$.

As mentioned, $\mathrm{PBC}$ is a disease which predominantly affects females, with the female-to-male ratios ranging from $9: 1$ to $22: 1[114,115]$. As such, few studies have taken into account PBC in men from both a pathogenic, as well as clinical viewpoint. The vast majority of $\mathrm{PBC}$ studies have been conducted on female patients. This review will examine the literature surrounding $\mathrm{PBC}$ in men, from a clinical and experimental standpoint (Table 1). We will also review the current literature which may, in part, explain why PBC rarely affects men and predominantly affects women.

1.1. PBC in Males: Case Reports and Epidemiological Studies. $\mathrm{PBC}$ occurring in males is relatively infrequent, which is 
reflected by the scarcity of studies examining PBC in males which are largely limited to case reports and small studies. The only twin study conducted in PBC consisted only of female pairs [95]. Brown and colleagues report PBC in a set of brothers, although the diagnosis in these early cases is questionable [116]. Tanaka et al. [117] notes two sets of brothers with PBC (one set in Britain and the other in France) in addition to several father-daughter and two brother-sister pairs. Unfortunately, the AMA status and clinical course of these patients are unknown [117]. Another set of brothers with a definitive diagnosis of PBC is followed up by the Barcelona group. Lazaridis and colleagues examined AMA status in 306 first-degree relatives of 350 PBC patients and found that AMA was present in $7.8 \%$ of brothers, $3.7 \%$ of fathers, and $0 \%$ of sons of PBC patients. It was not indicated whether the proband of the AMA-positive male's relatives were male or female [118]. The rarity of these case reports reflects the sporadic occurrence of PBC in males, which has also been demonstrated in epidemiological studies.

The female preponderance of PBC is reflected in several large epidemiological studies, and risk factors indicated in these studies tend to focus on those related to women [119122]. A recent study by Corpechot and colleagues involved a French cohort of 222 PBC patients and 509 controls, all administered a questionnaire regarding demographic, lifestyle, and health factors [119]. In that study, $11 \%$ of the PBC patients were male, as were $15 \%$ of the control group. Several risk factors indicated include a history of recurrent urinary tract infection (rUTI), smoking, and family history of PBC, as well as oestrogen deficiency [119]. There were no risk factors indicated which were related to male sex [119]. A study by Prince et al. [122] involved two groups of PBC patients, one consisting of 318 patients from an epidemiological study, and the other group consisted of 2258 patients from a PBC support group [122]. The control group consisted of 2438 matched controls. Among PBC patients from the epidemiological study group, $8 \%$ were male, compared to $7 \%$ in the support group [122], which are similar rates to those found by another group [121]. Again, no specific risk factors were indentified for males, although it was noted in the study by Prince and colleague [122] that less than $1 \%$ of males had a history of hair dye use, compared to over $50 \%$ of females, which is of interest given that hair dyes have been implicated as a possible risk factor for PBC development. One of the largest epidemiological studies carried out included 1032 PBC patients from 23 tertiary care centres and 1041 controls, all administered a telephone questionnaire [120]. Among PBC patients, 7\% were males compared to $8 \%$ of the control group. Again, there were no specific risk factors for males indicated [120]. These epidemiological studies have not identified any risk factors which are overtly male-specific, in contrast to several female-specific risk factors such as oestrogen deficiency. All studies demonstrated smoking and rUTI as risk factors [119123], although it is unclear what proportion of males had a significant history of smoking or rUTI. As well, a recent study has indicated that rUTI occurs before PBC diagnosis in a large proportion of $\mathrm{PBC}$ patients but did not indicate what percentage of males had a history of rUTI [124]. The proportion of males with a history of rUTI warrants further investigation.

It is possible that mechanisms such as molecular mimicry with $E$. coli and other organisms are involved in both men and women $[51,123]$. The development of experimental autoimmune cholangiopathy resembling $\mathrm{PBC}$ has been described in a 24-month-old C57BL/6 male mouse, after infection with $H$. pylori [125]. Liver histology demonstrated nonsuppurative, destructive cholangitis, peribiliary lymphoplasmacytic infiltration, and bridging fibrosis [125]. Serum antivacuolating toxin IgG levels were elevated in this mouse, compared to 13 other mice infected with H. pylori [125]. Those authors suggested that PBC may have developed due to molecular mimicry via anti-VacA antibodies [125]. However, Koutsoumpas and colleagues [126] highlighted that Goo et al. [125] did not specify if anti-PDC-E2 (AMAs) were present in the mouse. Further studies demonstrated insignificant homologous regions between $H$. pylori and PDC-E2 [126]. Inhibition studies abolished reactivity to PDC-E2 but not to VacA, and reciprocal studies using antiVacA did not inhibit anti-PDC-E2 reactivity [126]. It was therefore unlikely that $H$. pylori infection was related to the development of PBC by mechanisms of molecular mimicry.

Exposure to environmental toxins has also not been studied in great detail, although this may be of particular interest in regards to $\mathrm{PBC}$ in men, based on occupational exposure. It has been noted that some clusters of PBC patients have higher rates of affected males compared to the general population, and some of these clusters are centred around coal mines and steel working industries, which are predominantly employed by men [68]. These observations may warrant further study as to the occupational exposures of men with PBC.

\subsection{Clinical, Biochemical, and Histopathological Differences} in Male versus Female PBC. Clinical, biochemical, and histopathological differences in men versus women with PBC have been investigated in several early studies [52, 127, 128] (Table 1). One of these was conducted at the Armed Forces Institute of Pathology and involved 30 male and 30 age-matched female $\mathrm{PBC}$ patients, all AMA positive, with five of the 30 men being asymptomatic [127]. In addition to histological studies, symptoms and biochemical indices were also compared in each group. It was found that females experienced pruritus as a single symptom more often than males, in addition to experiencing more abdominal pain/discomfort as well as constitutional symptoms (malaise, anorexia, weight loss, fatigue, weight loss) [127]. In contrast, males experienced more jaundice, jaundice with pruritus, and upper gastrointestinal bleeding compared to females [127]. From a biochemical standpoint, ALP was slightly higher in symptomatic males compared to asymptomatic males, with both being higher than females in general [127]. Histologically, the only difference found was that symptomatic female patients had more piecemeal necrosis and that symptomatic males had more stainable copper storage than asymptomatic males [127]. Symptomatic females 


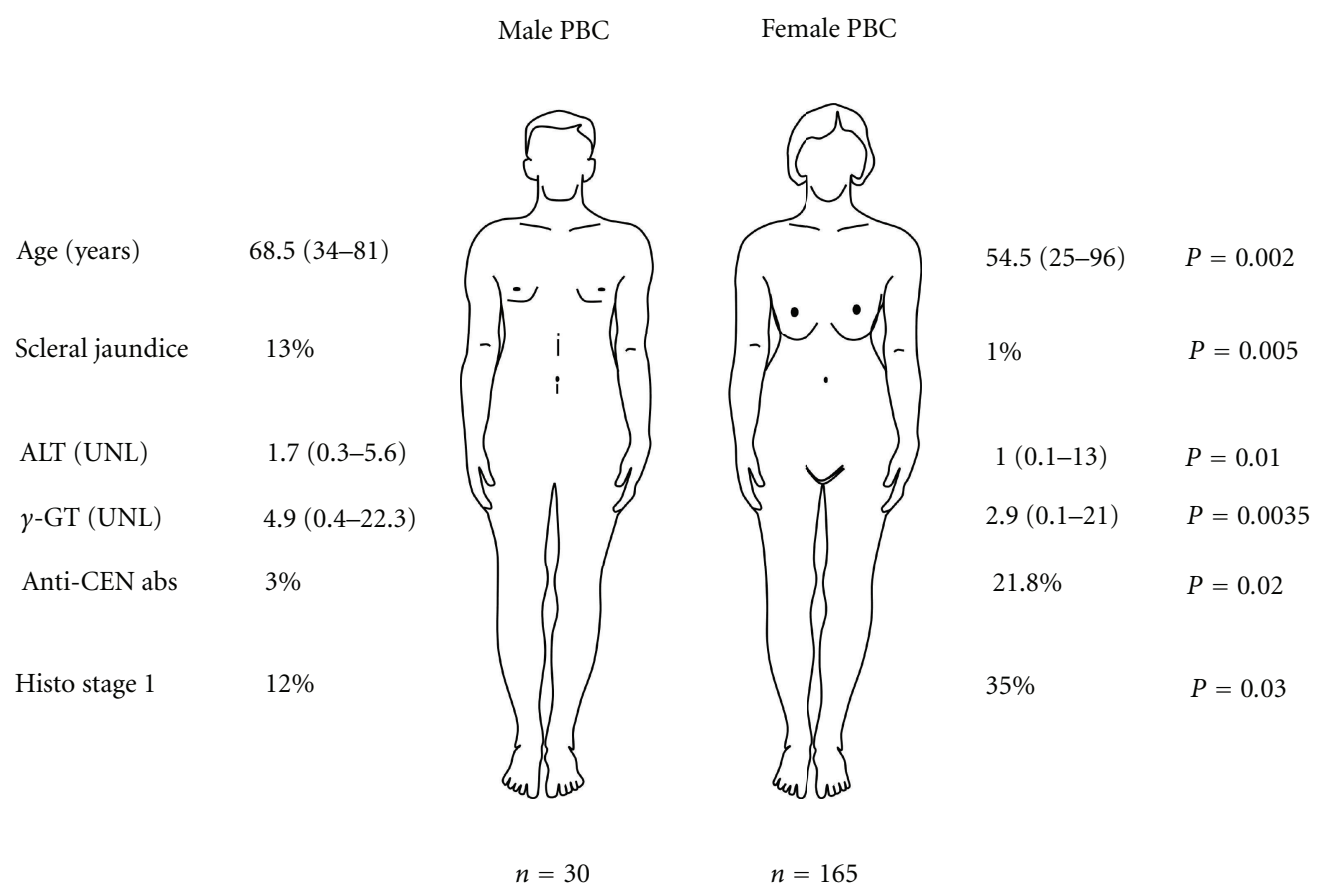

FIGURE 2: Clinical and Laboratory differences between women and men with PBC. The figure illustrates the significant differences between the Italian cohorts of men and women with PBC analysed by Muratori et al. [52] Only the parameters that reached statistically significant difference are given. More details are provided within the text; UNL, upper normal level; histo, histological; CEN, centromere; abs, antibodies.

had more marked pseudoxanthomatous transformation than asymptomatic females [127]. That study concluded that there was little difference in male versus female PBC.

Another study, conducted by a specialist liver unit at King's College Hospital, compared the clinical and biochemical profiles of males and females with $\mathrm{PBC}$, in addition to long-term outcome [128]. Thirty-nine (39) men and 191 women with $\mathrm{PBC}$ were enrolled, with the age of diagnosis and disease severity being similar in both groups. Pruritus was found to be less common in males than females $(45 \%$ versus $68 \%$ ), and it was suggested that female sex hormones may be linked with pruritus, as there was an increased frequency of women reporting pruritus beginning with the administration of oral contraceptives, as well as during pregnancy [128]. Much like the earlier study [127], the group at King's College Hospital found that gastrointestinal bleeding was more common among males patients (23\%) than female patients $(15 \%)$, although this was not indicated to be statistically significant [128]. In fact, the only statistically significant finding in regards to clinical signs was that females demonstrated skin pigmentation more often than males (55\% versus 35\%) [128]. Concomitant autoimmune diseases were also examined between the two groups. Sicca symptoms were present in $33 \%$ of females and $15 \%$ males, scleroderma in $13 \%$ of females and $8 \%$ of males, and Raynauds in 13\% females and 3\% of males [128]. These findings suggest that females were more likely to suffer concomitant autoimmune disease than males. Interestingly, that study was the first to report an increased frequency of type 2 diabetes in male PBC patients [128]. As well, men with $\mathrm{PBC}$ had a higher frequency of hepatoma, which has also been found in other studies [128-130]. No significant differences were observed in regards to AMA, biochemistry, histology, or survival [128]. An Italian study [52] compared clinical and serological data of 30 consecutive male and 165 female PBC patients (Figure 2). Histology was available in $83 \%$ of the males and $79 \%$ of females. Clinically, there was a significant difference in age between the two groups, with males presenting at a median age of 68.5 years compared to 54.5 years in females [52]. Scleral jaundice was more common among males $(13 \%)$ than females $(11 \%)$, which was the only statistically significant clinical difference among the two groups (Figure 2). However, it should be noted that $64 \%$ of males and $51.5 \%$ of females were asymptomatic at the time of diagnosis, although this was not statistically significant [52]. Biochemically, males had higher levels of ALT and $\gamma \mathrm{GT}$ [52]. Analysis of biopsy specimens revealed that stage I was present in $35 \%$ of females compared to $12 \%$ of males, although $36 \%$ and $28 \%$ of males were in stages III and IV, respectively, compared to $19 \%$ of females in both stages [52]. However, this was not found to be statistically significant. Immunological profiles regarding AMA and ANA were not different between the two groups, although a higher frequency of anti-centromere activity was noted in females $(21.4 \%)$ than in males (3\%) [52]. That study concluded that more advanced disease in males was most likely due to delayed diagnosis in this group, in which $\mathrm{PBC}$ is not initially suspected [52]. 
The studies above suggest that although there does not appear to be a significant difference in the biochemical, histological, and immunological profiles of males and females with PBC, symptomatology does appear to be different, with males being more likely to experience potentially life threatening complications such as upper gastrointestinal bleeding and hepatoma. It is not clear whether this is due to the advanced stage that these patients are presented due a delay in reaching a definite diagnosis of PBC.

1.3. Autoantibody Profiles in Men versus Women. Although earlier studies addressed AMA positivity between males and females, none have examined the AMA specificities in men and women. Nalbandian and colleagues [114] conducted a study to determine if there were serological differences between men and women. That study involved 46 men and 42 women, all with high titer AMA [114]. Reactivity patterns were similar in both groups: PDC-E2 (72\% males, $76 \%$ females), E3BP/Protein X (63\% males, $62 \%$ females), BCOADC-E2 (41\% males, 50\% females), and OGDC-E2 (24\% males, $17 \%$ females) [114]. Testing of the optical densities did not reveal any significant difference, which leads to the conclusion that there was no difference of AMA reactivity between males and females [114].

1.4. X Monosomy. Given the female preponderance of PBC, the role of the $\mathrm{X}$ chromosome has been investigated [131, 132]. Links between the $X$ chromosome and immunity have been strengthened by clinical data, such as IPEX and XSCID syndromes which are caused by mutations on Xp11 and Xq13.1, respectively [131]. As well, X chromosome defects are more frequent in women with late-onset autoimmune disease $[60,132-134]$. Skewed $\mathrm{X}$ inactivation appears to be a feature of several autoimmune diseases which are concomitant with PBC, such as systemic sclerosis $[135,136]$, autoimmune thyroid disease [137], and Sjogren's syndrome [138], but not in PBC [139].

Selmi also indicates that epigenetic factors, such as $\mathrm{X}$ chromosome inactivation, may also be involved in the development of PBC, as well as variable concordance rates of PBC among twins [95]. These theories are of interest, given the increased $\mathrm{X}$ chromosome monosomy rate in the peripheral lymphocytes of female patients with PBC [60, 133, 140]. Mitchell et al. [140] analysed 125 variable X chromosome inactivation status genes in peripheral blood mRNA and DNA from MZ discordant and concordant pairs. Consistently downregulated genes included CLIC2 and PIN4 in the twin with PBC, which was not found in the healthy twin or in control subjects [140]. Partial or variable methylation was found in both genes and did not predict transcript levels or X inactivation status [140]. That study demonstrates the complexity of epigenetic factors which must be considered not only in twin studies but also in the comparison of men and women with PBC.

1.5. Immunological Differences in Males and Females. Immunological differences may also explain the variable rates of PBC between men and women [134]. For example, females demonstrate enhanced antibody production and cell-mediated responses following immunization [141], in addition to having an increased CD4 T-cell count [142]. Males show increased inflammatory responses to infectious organisms [143], and sex hormones appear to effect cytokine production, B-cell maturation, homing of lymphocytes, and antigen presentation, which is of interest given the association between hormone replacement therapy and PBC [134]. As well, sex hormones can affect immune cell functioning by binding to steroid receptors [144]. Oestrogen and androgen receptors are expressed on B cells, whereas CD8 T cells, monocytes, neutrophils, and NK cells express oestrogen but not androgen receptors [144]. One study has demonstrated that oestrogen treatment of peripheral blood mononuclear cells from SLE patients increased IgG production, as well as anti-dsDNA autoantibody levels $[145,146]$. Testosterone was found to decrease IgG and IgM production by peripheral blood mononuclear cells in healthy males and females [147]. Despite these findings, it remains unclear as to what role sex hormones play in the pathogenesis of $\mathrm{PBC}$, as well as the preponderance of $\mathrm{PBC}$ in females versus males.

\section{Conclusion}

The reasons underlying the rarity of $\mathrm{PBC}$ in males remain elusive. Studies have failed to demonstrate significant differences in the biochemical, immunological and histological features of $\mathrm{PBC}$ in men and women. Clinically, there does appear to be some differences between the sexes, with females tending to present with pruritus more than males, and males are at higher risk of developing gastrointestinal bleeding and hepatoma. The reasons for this are unclear. Risk factors for PBC have been reasonably well defined, although these factors do not demonstrate any male-specific risk factors, such as occupational exposures, which is a point that needs to be addressed. As well, rUTI has been demonstrated as a risk factor in females, but the proportion of male PBC patients with a history of rUTI remains unknown. The role of sex hormones in the pathogenesis of $\mathrm{PBC}$ also requires further study, as this may also shed some light on why $\mathrm{PBC}$ is so rare in males.

\section{Abbreviations}

ALP: $\quad$ Alkaline phosphatase

AMAs: Antimitochondrial antibodies

ANAs: Antinuclear antibodies

BEC: $\quad$ Biliary epithelial cell

E.coli: Escherichia coli

H. pylori: Helicobacter pylori

PBC: $\quad$ Primary biliary cirrhosis

PDC: Pyruvate dehydrogenase complex

RA: Rheumatoid arthritis

SLE: Systemic lupus erythematosus

rUTI: Recurrent urinary tract infection.

\section{Authors' Contribution}

E. I. Rigopoulou and D. P. Bogdanos equally contributed in this paper. 


\section{Acknowledgment}

We thank Dr. Yoh Zen, King's College Hospital, London, for providing the histological images.

\section{References}

[1] M. M. Kaplan and M. E. Gershwin, "Primary biliary cirrhosis," New England Journal of Medicine, vol. 353, no. 12, pp. 1261-1273, 2005.

[2] S. Hohenester, R. P. J. Oude-Elferink, and U. Beuers, "Primary biliary cirrhosis," Seminars in Immunopathology, vol. 31, no. 3, pp. 283-307, 2009.

[3] J. Neuberger, "Primary biliary cirrhosis," The Lancet, vol. 350, no. 9081, pp. 875-879, 1997.

[4] D.S. Smyk, E. I. Rigopoulou, A. Lleo et al., "Immunopathogenesis of primary biliary cirrhosis: an old wives' tale," Immunity \& Ageing, vol. 8, no. 1, p. 12, 2011.

[5] O. E. W. James, R. Bhopal, D. Howel, J. Gray, A. D. Burt, and J. V. Metcalf, "Primary biliary cirrhosis once rare, now common in the United Kingdom?” Hepatology, vol. 30, no. 2, pp. 390-394, 1999.

[6] S. Sood, P. J. Gow, J. M. Christie, and P. W. Angus, "Epidemiology of primary biliary cirrhosis in Victoria, Australia: high prevalence in migrant populations," Gastroenterology, vol. 127, no. 2, pp. 470-475, 2004.

[7] W. R. Kim, K. D. Lindor, G. R. Locke et al., "Epidemiology and natural history of primary biliary cirrhosis in a U.S. community," Gastroenterology, vol. 119, no. 6, pp. 16311636, 2000.

[8] M. G. Peters, A. M. Di Bisceglie, K. V. Kowdley et al., "Differences between Caucasian, African American, and Hispanic patients with primary biliary cirrhosis in the United States," Hepatology, vol. 46, no. 3, pp. 769-775, 2007.

[9] R. G. Watson, P. W. Angus, M. Dewar, B. Goss, R. B. Sewell, and R. A. Smallwood, "Low prevalence of primary biliary cirrhosis in Victoria, Australia. Melbourne Liver Group," Gut, vol. 36, no. 6, pp. 927-930, 1995.

[10] A. C. Anand, E. Elias, and J. M. Neuberger, "End-stage primary biliary cirrhosis in a first generation migrant south Asian population," European Journal of Gastroenterology and Hepatology, vol. 8, no. 7, pp. 663-666, 1996.

[11] N. Guanabens, D. Cerda, A. Monegal et al., "Low bone mass and severity of cholestasis affect fracture risk in patients with primary biliary cirrhosis," Gastroenterology, vol. 138, no. 7, pp. 2348-2356, 2010.

[12] A. Parés and N. Guañabens, "Osteoporosis in primary biliary cirrhosis: pathogenesis and treatment," Clinics in Liver Disease, vol. 12, no. 2, pp. 407-424, 2008.

[13] C. Rigamonti, D. P. Bogdanos, M. G. Mytilinaiou, D. S. Smyk, E. I. Rigopoulou, and A. K. Burroughs, "Primary biliary cirrhosis associated with systemic sclerosis: diagnostic and clinical challenges," International Journal of Rheumatology, vol. 2011, Article ID 976427, 12 pages, 2011.

[14] A. Pares, L. Caballeria, and J. Rodes, "Excellent longterm survival in patients with primary biliary cirrhosis and biochemical response to ursodeoxycholic Acid," Gastroenterology, vol. 130, no. 3, pp. 715-720, 2006.

[15] D. P. Bogdanos, H. Baum, and D. Vergani, "Antimitochondrial and other autoantibodies," Clinics in Liver Disease, vol. 7, no. 4, pp. 759-777, 2003.

[16] D. P. Bogdanos, P. Invernizzi, I. R. Mackay, and D. Vergani, "Autoimmune liver serology: current diagnostic and clinical challenges," World Journal of Gastroenterology, vol. 14, no. 21, pp. 3374-3387, 2008.

[17] J. C. Courvalin and H. J. Worman, "Nuclear envelope protein autoantibodies in primary biliary cirrhosis," Seminars in Liver Disease, vol. 17, no. 1, pp. 79-90, 1997.

[18] C. Szostecki, H. H. Guldner, and H. Will, "Autoantibodies against 'nuclear dots' in primary biliary cirrhosis," Seminars in Liver Disease, vol. 17, no. 1, pp. 71-78, 1997.

[19] H. Liu, G. L. Norman, Z. Shums et al., "PBC Screen: an IgG/IgA dual isotype ELISA detecting multiple mitochondrial and nuclear autoantibodies specific for primary biliary cirrhosis," Journal of Autoimmunity, vol. 35, no. 4, pp. 436442, 2010.

[20] C. Dähnrich, A. Pares, L. Caballeria et al., "New ELISA for detecting primary biliary cirrhosis-specific antimitochondrial antibodies," Clinical Chemistry, vol. 55, no. 5, pp. 978985, 2009.

[21] D. P. Bogdanos and L. Komorowski, "Disease-specific autoantibodies in primary biliary cirrhosis," Clinica Chimica Acta, vol. 412, no. 7-8, pp. 502-512, 2011.

[22] A. Granito, P. Muratori, C. Quarneti, G. Pappas, R. Cicola, and L. Muratori, "Antinuclear antibodies as ancillary markers in primary biliary cirrhosis," Expert Review of Molecular Diagnostics, vol. 12, no. 1, pp. 65-74, 2012.

[23] P. Muratori, A. Granito, G. Pappas et al., "The serological profile of the autoimmune hepatitis/primary biliary cirrhosis overlap syndrome," American Journal of Gastroenterology, vol. 104, no. 6, pp. 1420-1425, 2009.

[24] L. Muratori, A. Granito, P. Muratori, G. Pappas, and F. B. Bianchi, "Antimitochondrial antibodies and other antibodies in primary biliary cirrhosis: diagnostic and prognostic value," Clinics in Liver Disease, vol. 12, no. 2, pp. 261-276, 2008.

[25] M. D. Van Norstrand, M. Malinchoc, K. D. Lindor et al., "Quantitative measurement of autoantibodies to recombinant mitochondrial antigens in patients with primary biliary cirrhosis: relationship of levels of autoantibodies to disease progression," Hepatology, vol. 25, no. 1, pp. 6-11, 1997.

[26] E. I. Rigopoulou, D. P. Bogdanos, C. Liaskos et al., "Antimitochondrial antibody immunofluorescent titres correlate with the number and intensity of immunoblot-detected mitochondrial bands in patients with primary biliary cirrhosis," Clinica Chimica Acta, vol. 380, no. 1-2, pp. 118-121, 2007.

[27] E. I. Rigopoulou, E. T. Davies, D. P. Bogdanos et al., "Antimitochondrial antibodies of immunoglobulin G3 subclass are associated with a more severe disease course in primary biliary cirrhosis," Liver International, vol. 27, no. 9, pp. 12261231, 2007.

[28] E. I. Rigopoulou, E. T. Davies, A. Pares et al., "Prevalence and clinical significance of isotype specific antinuclear antibodies in primary biliary cirrhosis," Gut, vol. 54, no. 4, pp. 528-532, 2005.

[29] K. Miyachi, R. W. Hankins, H. Matsushima et al., "Profile and clinical significance of anti-nuclear envelope antibodies found in patients with primary biliary cirrhosis: a multicenter study," Journal of Autoimmunity, vol. 20, no. 3, pp. 247254, 2003.

[30] M. Nakamura, H. Kondo, T. Mori et al., "Anti-gp210 and anti-centromere antibodies are different risk factors for the progression of primary biliary cirrhosis," Hepatology, vol. 45, no. 1, pp. 118-127, 2007.

[31] D. P. Bogdanos, C. Liaskos, A. Pares et al., "Anti-gp210 antibody mirrors disease severity in primary biliary cirrhosis," Hepatology, vol. 45, no. 6, pp. 1583-1584, 2007. 
[32] D. P. Bogdanos, C. Liaskos, E. I. Rigopoulou, and G. N. Dalekos, "Anti-mitochondrial antibodies in patients with systemic lupus erythematosus: revealing the unforeseen," Clinica Chimica Acta, vol. 373, no. 1-2, pp. 183-185, 2006.

[33] D. P. Bogdanos, A. Pares, J. Rodes, and D. Vergani, "Primary biliary cirrhosis specific antinuclear antibodies in patients from Spain," The American Journal of Gastroenterology, vol. 99, no. 4, pp. 763-765, 2004.

[34] D. P. Bogdanos, D. Vergani, P. Muratori, L. Muratori, and F. B. Bianchi, "Specificity of anti-sp100 antibody for primary biliary cirrhosis," Scandinavian Journal of Gastroenterology, vol. 39, no. 4, pp. 405-407, 2004.

[35] P. Invernizzi, M. Podda, P. M. Battezzati et al., "Autoantibodies against nuclear pore complexes are associated with more active and severe liver disease in primary biliary cirrhosis," Journal of Hepatology, vol. 34, no. 3, pp. 366-372, 2001.

[36] D. P. Bogdanos and G. N. Dalekos, "Enzymes as target antigens of liver-specific autoimmunity: the case of cytochromes P450s," Current Medicinal Chemistry, vol. 15, no. 22, pp. 2285-2292, 2008.

[37] J. Wesierska-Gadek, E. Penner, P. M. Battezzati et al., "Correlation of initial autoantibody profile and clinical outcome in primary biliary cirrhosis," Hepatology, vol. 43, no. 5, pp. 1135-1144, 2006.

[38] S. Oertelt, R. Rieger, C. Selmi et al., "A sensitive bead assay for antimitochondrial antibodies: chipping away at AMAnegative primary biliary cirrhosis," Hepatology, vol. 45, no. 3, pp. 659-665, 2007.

[39] G. M. Hirschfield, X. Liu, Y. Han et al., "Variants at IRF5TNPO3, 17q12-21 and MMEL1 are associated with primary biliary cirrhosis," Nature Genetics, vol. 42, no. 8, pp. 655-657, 2010.

[40] D. Vergani and D. P. Bogdanos, "Positive markers in AMAnegative PBC," American Journal of Gastroenterology, vol. 98, no. 2, pp. 241-243, 2003.

[41] J. V. Metcalf, H. C. Mitchison, J. M. Palmer, D. E. Jones, M. F. Bassendine, and O. F. W. James, "Natural history of early primary biliary cirrhosis," The Lancet, vol. 348, no. 9039, pp. 1399-1402, 1996.

[42] H. C. Mitchison, M. F. Bassendine, A. Hendrick et al., "Positive antimitochondrial antibody but normal alkaline phosphatase: is this primary biliary cirrhosis?" Hepatology, vol. 6, no. 6, pp. 1279-1284, 1986.

[43] J. V. Metcalf, R. S. Bhopal, J. Gray, D. Howel, and O. F. W. James, "Incidence and prevalence of primary biliary cirrhosis in the city of Newcastle upon Tyne, England," International Journal of Epidemiology, vol. 26, no. 4, pp. 830-836, 1997.

[44] K. E. Kisand, K. V. Kisand, A. L. Karvonen et al., "Antibodies to pyruvate dehydrogenase in primary biliary cirrhosis: correlation with histology," Acta Pathologica, Microbiologica et Immunologica Scandinavica, vol. 106, no. 9, pp. 884-892, 1998.

[45] K. D. Lindor, M. E. Gershwin, R. Poupon, M. Kaplan, N. V. Bergasa, and E. J. Heathcote, "Primary biliary cirrhosis," Hepatology, vol. 50, no. 1, pp. 291-308, 2009.

[46] M. E. Gershwin and I. R. Mackay, "Primary biliary cirrhosis: paradigm or paradox for autoimmunity," Gastroenterology, vol. 100, no. 3, pp. 822-833, 1991.

[47] M. E. Gershwin and I. R. Mackay, "The causes of primary biliary cirrhosis: convenient and inconvenient truths," Нераtology, vol. 47, no. 2, pp. 737-745, 2008.

[48] I. R. Mackay, S. Whittingham, S. Fida et al., "The peculiar autoimmunity of primary biliary cirrhosis," Immunological Reviews, vol. 174, pp. 226-237, 2000.
[49] D. P. Bogdanos and D. Vergani, "Origin of cross-reactive autoimmunity in primary biliary cirrhosis," Liver International, vol. 26, no. 6, pp. 633-635, 2006.

[50] D. P. Bogdanos and D. Vergani, "Bacteria and primary biliary cirrhosis," Clinical Reviews in Allergy and Immunology, vol. 36, no. 1, pp. 30-39, 2009.

[51] D. P. Bogdanos, H. Baum, D. Vergani, and A. K. Burroughs, "The role of E. coli infection in the pathogenesis of primary biliary cirrhosis," Disease Markers, vol. 29, no. 6, pp. 301-311, 2010.

[52] P. Muratori, A. Granito, G. Pappas et al., "Clinical and serological profile of primary biliary cirrhosis in men," QJM, vol. 100, no. 8, pp. 534-535, 2007.

[53] R. J. Q. McNally, S. Ducker, and O. F. W. James, "Are transient environmental agents involved in the cause of primary biliary cirrhosis? Evidence from space-time clustering analysis," Hepatology, vol. 50, no. 4, pp. 1169-1174, 2009.

[54] D. Alvaro, P. Invernizzi, P. Onori et al., "Estrogen receptors in cholangiocytes and the progression of primary biliary cirrhosis," Journal of Hepatology, vol. 41, no. 6, pp. 905-912, 2004.

[55] K. Amano, P. S. C. Leung, R. Rieger et al., "Chemical xenobiotics and mitochondrial autoantigens in primary biliary cirrhosis: identification of antibodies against a common environmental, cosmetic, and food additive, 2-octynoic acid," Journal of Immunology, vol. 174, no. 9, pp. 5874-5883, 2005.

[56] K. Amano, P. S. C. Leung, Q. Xu et al., "Xenobioticinduced loss of tolerance in rabbits to the mitochondrial autoantigen of primary biliary cirrhosis is reversible," Journal of Immunology, vol. 172, no. 10, pp. 6444-6452, 2004.

[57] D. Bogdanos, T. Pusl, C. Rust, D. Vergani, and U. Beuers, "Primary biliary cirrhosis following lactobacillus vaccination for recurrent vaginitis," Journal of Hepatology, vol. 49, no. 3, pp. 466-473, 2008.

[58] D. P. Bogdanos, H. Baum, M. Okamoto et al., "Primary biliary cirrhosis is characterized by IgG3 antibodies crossreactive with the major mitochondrial autoepitope and its lactobacillus mimic," Hepatology, vol. 42, no. 2, pp. 458-465, 2005.

[59] D. P. Bogdanos, H. Baum, U. C. Sharma et al., "Antibodies against homologous microbial caseinolytic proteases $\mathrm{P}$ characterise primary biliary cirrhosis," Journal of Hepatology, vol. 36, no. 1, pp. 14-21, 2002.

[60] P. Invernizzi, M. Miozzo, P. M. Battezzati et al., "Frequency of monosomy $\mathrm{X}$ in women with primary biliary cirrhosis," The Lancet, vol. 363, no. 9408, pp. 533-535, 2004.

[61] D. E. Jones, "Pathogenesis of primary biliary cirrhosis," Gut, vol. 56, no. 11, pp. 1615-1624, 2007.

[62] D. E. J. Jones and P. T. Donaldson, "Genetic factors in the pathogenesis of primary biliary cirrhosis," Clinics in Liver Disease, vol. 7, no. 4, pp. 841-864, 2003.

[63] C. Selmi and M. E. Gershwin, "The role of environmental factors in primary biliary cirrhosis," Trends in Immunology, vol. 30, no. 8, pp. 415-420, 2009.

[64] C. Selmi, P. Invernizzi, M. Zuin, M. Podda, and M. E. Gershwin, "Genetics and geoepidemiology of primary biliary cirrhosis: following the footprints to disease etiology," Seminars in Liver Disease, vol. 25, no. 3, pp. 265-280, 2005.

[65] C. Selmi, P. Invernizzi, M. Zuin, M. Podda, M. F. Seldin, and M. E. Gershwin, "Genes and (auto)immunity in primary biliary cirrhosis," Genes and Immunity, vol. 6, no. 7, pp. 543556, 2005.

[66] X. Liu, P. Invernizzi, Y. Lu et al., "Genome-wide metaanalyses identify three loci associated with primary biliary cirrhosis," Nature Genetics, vol. 42, no. 8, pp. 658-660, 2010. 
[67] G. M. Hirschfield, X. Liu, C. Xu et al., "Primary biliary cirrhosis associated with HLA, IL12A, and IL12RB2 variants," New England Journal of Medicine, vol. 360, no. 24, pp. 2544 2555, 2009.

[68] D. Smyk, M. G. Mytilinaiou, E. I. Rigopoulou, and D. P. Bogdanos, "PBC triggers in water reservoirs, coal mining areas and waste disposal sites: from Newcastle to New York," Disease Markers, vol. 29, no. 6, pp. 337-344, 2010.

[69] D. Smyk, E. I. Rigopoulou, H. Baum, A. K. Burroughs, D. Vergani, and D. P. Bogdanos, "Autoimmunity and environment: am i at risk?" Clinical Reviews in Allergy and Immunology, vol. 42, no. 2, pp. 199-212, 2012.

[70] P. Invernizzi, C. Selmi, and M. E. Gershwin, "Update on primary biliary cirrhosis," Digestive and Liver Disease, vol. 42, no. 6, pp. 401-408, 2010.

[71] P. Invernizzi and M. E. Gershwin, "The genetic basis of primary biliary cirrhosis: premises, not promises," Gastroenterology, vol. 135, no. 4, pp. 1044-1047, 2008.

[72] L. Persani, M. Bonomi, A. Lleo et al. et al., "Increased loss of the Y chromosome in peripheral blood cells in male patients with autoimmune thyroiditis," Journal of Autoimmunity, vol. 38, no. 2-3, pp. 193-196, 2012.

[73] D. S. Smyk, E. I. Rigopoulou, L. Muratori, A. K. Burroughs, and D. P. Bogdanos, "Smoking as a risk factor for autoimmune liver disease: what we can learn from primary biliary cirrhosis," Annals of Hepatology, vol. 11, no. 1, pp. 7-14, 2012.

[74] G. M. Hirschfield and P. Invernizzi, "Progress in the genetics of primary biliary cirrhosis," Seminars in Liver Disease, vol. 31, no. 2, pp. 147-156, 2011.

[75] R. Y. Lan, C. Cheng, Z. X. Lian et al., "Liver-targeted and peripheral blood alterations of regulatory $\mathrm{T}$ cells in primary biliary cirrhosis," Hepatology, vol. 43, no. 4, pp. 729-737, 2006.

[76] M. S. Longhi, Y. Ma, D. P. Bogdanos, P. Cheeseman, G. Mieli-Vergani, and D. Vergani, "Impairment of CD4 ${ }^{+} \mathrm{CD} 25^{+}$ regulatory T-cells in autoimmune liver disease," Journal of Hepatology, vol. 41, no. 1, pp. 31-37, 2004.

[77] M. S. Longhi, Y. Ma, R. R. Mitry et al., "Effect of CD4 $4^{+} \mathrm{CD} 25^{+}$ regulatory T-cells on CD8 T-cell function in patients with autoimmune hepatitis," Journal of Autoimmunity, vol. 25, no. 1, pp. 63-71, 2005.

[78] R. Poupon, C. Ping, Y. Chretien et al. et al., "Genetic factors of susceptibility and of severity in primary biliary cirrhosis," Journal of Hepatology, vol. 49, no. 6, pp. 1038-1045, 2008.

[79] R. Poupon and R. E. Poupon, "Retrovirus infection as a trigger for primary biliary cirrhosis?" The Lancet, vol. 363, no. 9405 , pp. 260-261, 2004.

[80] D. P. Bogdanos, H. Baum, A. Grasso et al., "Microbial mimics are major targets of crossreactivity with human pyruvate dehydrogenase in primary biliary cirrhosis," Journal of Hepatology, vol. 40, no. 1, pp. 31-39, 2004.

[81] D. P. Bogdanos, M. Lenzi, M. Okamoto et al., "Multiple $\mathrm{viral} /$ self immunological cross-reactivity in liver kidney microsomal antibody positive hepatitis $C$ virus-infected patients is associated with the possession of HLA B51," International Journal of Immunopathology and Pharmacology, vol. 17, no. 1, pp. 83-92, 2004.

[82] N. Kerkar, K. Choudhuri, Y. Ma et al., "Cytochrome P4502D6193-212: a new immunodominant epitope and target of virus/self cross-reactivity in liver kidney microsomal autoantibody type 1-positive liver disease," Journal of Immunology, vol. 170, no. 3, pp. 1481-1489, 2003.

[83] D. P. Bogdanos, G. Mieli-Vergani, and D. Vergani, "Virus, liver and autoimmunity," Digestive and Liver Disease, vol. 32, no. 5, pp. 440-446, 2000.
[84] D. Polymeros, D. P. Bogdanos, R. Day, D. Arioli, D. Vergani, and A. Forbes, "Does cross-reactivity between mycobacterium avium paratuberculosis and human intestinal antigens characterize crohn's disease?" Gastroenterology, vol. 131, no. 1, pp. 85-96, 2006.

[85] L. Wen, Y. Ma, D. P. Bogdanos et al., "Pédiatrie autoimmune liver diseases: the molecular basis of humoral and cellular immunity," Current Molecular Medicine, vol. 1, no. 3, pp. 379-389, 2001.

[86] D. P. Bogdanos, H. Baum, F. Gunsar et al., "Extensive homology between the major immunodominant mitochondrial antigen in primary biliary cirrhosis and Helicobacter pylori does not lead to immunological cross-reactivity," Scandinavian Journal of Gastroenterology, vol. 39, no. 10, pp. 981-987, 2004.

[87] L. Muratori, D. P. Bogdanos, P. Muratori et al., "Susceptibility to thyroid disorders in hepatitis C," Clinical Gastroenterology and Hepatology, vol. 3, no. 6, pp. 595-603, 2005.

[88] S. Shimoda, M. Nakamura, H. Shigematsu et al., "Mimicry peptides of human PDC-E2 163-176 peptide, the immunodominant T- cell epitope of primary biliary cirrhosis," Hepatology, vol. 31, no. 6, pp. 1212-1216, 2000.

[89] S. Shimoda, J. Van De Water, A. Ansari et al., "Identification and precursor frequency analysis of a common T cell epitope motif in mitochondrial autoantigens in primary biliary cirrhosis," Journal of Clinical Investigation, vol. 102, no. 10, pp. 1831-1840, 1998.

[90] D. P. Bogdanos, H. Smith, Y. Ma, H. Baum, G. Mieli-Vergani, and D. Vergani, "A study of molecular mimicry and immunological cross-reactivity between hepatitis B surface antigen and myelin mimics," Clinical and Developmental Immunology, vol. 12, no. 3, pp. 217-224, 2005.

[91] D. P. Bogdanos, H. Baum, P. Butler et al., "Association between the primary biliary cirrhosis specific anti-sp100 antibodies and recurrent urinary tract infection," Digestive and Liver Disease, vol. 35, no. 11, pp. 801-805, 2003.

[92] H. Baum, D. P. Bogdanos, and D. Vergani, "Antibodies to Clp protease in primary biliary cirrhosis: possible role of a mimicking T-cell epitope," Journal of Hepatology, vol. 34, no. 5, pp. 785-787, 2001.

[93] D. Vergani, M. S. Longhi, D. P. Bogdanos, Y. Ma, and G. Mieli-Vergani, "Autoimmune hepatitis," Seminars in Immunopathology, vol. 31, no. 3, pp. 421-435, 2009.

[94] S. Abu-Mouch, C. Selmi, G. D. Benson et al., "Geographic clusters of primary biliary cirrhosis," Clinical and Developmental Immunology, vol. 10, no. 2-4, pp. 127-131, 2003.

[95] C. Selmi, M. J. Mayo, N. Bach et al., "Primary biliary cirrhosis in monozygotic and dizygotic twins: genetics, epigenetics, and environment," Gastroenterology, vol. 127, no. 2, pp. 485492, 2004.

[96] D. Smyk, E. Cholongitas, S. Kriese, E. I. Rigopoulou, and D. P. Bogdanos, "Primary biliary cirrhosis: family stories," Autoimmune Diseases, vol. 2011, Article ID 189585, 11 pages, 2011.

[97] D. P. Bogdanos, D. S. Smyk, E. I. Rigopoulou et al., "Twin studies in autoimmune disease: genetics, gender and environment," Journal of Autoimmunity, vol. 38, no. 2-3, pp. 156$169,2012$.

[98] P. Invernizzi, "Human leukocyte antigen in primary biliary cirrhosis: an old story now reviving," Hepatology, vol. 54, no. 2, pp. 714-723, 2011.

[99] P. Invernizzi, C. Selmi, F. Poli et al., "Human leukocyte antigen polymorphisms in Italian primary biliary cirrhosis: a 
multicenter study of 664 patients and 1992 healthy controls," Hepatology, vol. 48, no. 6, pp. 1906-1912, 2008.

[100] G. F. Mells, J. A. Floyd, K. I. Morley et al., "Genome-wide association study identifies 12 new susceptibility loci for primary biliary cirrhosis," Nature genetics, vol. 43, no. 4, pp. 329-332, 2011.

[101] A. Tanaka, P. Invernizzi, H. Ohira et al., "Replicated association of 17q12-21 with susceptibility of primary biliary cirrhosis in a Japanese cohort," Tissue Antigens, vol. 78, no. 1, pp. 65-68, 2011.

[102] A. Tanaka, H. Ohira, K. Kikuchi et al., "Genetic association of Fc receptor-like 3 polymorphisms with susceptibility to primary biliary cirrhosis: ethnic comparative study in Japanese and Italian patients," Tissue Antigens, vol. 77, no. 3, pp. 239243, 2011.

[103] S. Shimoda, M. Nakamura, H. Ishibashi, K. Hayashida, and Y. Niho, "HLA DRB4 0101-restricted immunodominant T cell autoepitope of pyruvate dehydrogenase complex in primary biliary cirrhosis: evidence of molecular mimicry in human autoimmune diseases," Journal of Experimental Medicine, vol. 181, no. 5, pp. 1835-1845, 1995.

[104] S. Shimoda, K. Harada, H. Niiro et al., "Interaction between Toll-like receptors and natural killer cells in the destruction of bile ducts in primary biliary cirrhosis," Hepatology, vol. 53, no. 4, pp. 1270-1281, 2011.

[105] K. Harada, S. Shimoda, H. Ikeda et al., "Significance of periductal Langerhans cells and biliary epithelial cell-derived macrophage inflammatory protein- $3 \alpha$ in the pathogenesis of primary biliary cirrhosis," Liver International, vol. 31, no. 2, pp. 245-253, 2011.

[106] K. Harada, S. Shimoda, Y. Sato, K. Isse, H. Ikeda, and Y. Nakanuma, "Periductal interleukin-17 production in association with biliary innate immunity contributes to the pathogenesis of cholangiopathy in primary biliary cirrhosis," Clinical and Experimental Immunology, vol. 157, no. 2, pp. 261-270, 2009.

[107] K. Harada and Y. Nakanuma, "Cholangiopathy with respect to biliary innate immunity," International Journal of Hepatology, vol. 2012, Article ID 793569, 10 pages, 2012.

[108] H. Kita, Z. X. Lian, J. Van De Water et al., "Identification of HLA-A2-restricted $\mathrm{CD}^{+}$cytotoxic $\mathrm{T}$ cell responses in primary biliary cirrhosis: $\mathrm{T}$ cell activation is augmented by immune complexes cross-presented by dendritic cells," Journal of Experimental Medicine, vol. 195, no. 1, pp. 113-123, 2002.

[109] H. Kita, S. Matsumura, X. S. He et al., "Quantitative and functional analysis of PDC-E2-specific autoreactive cytotoxic T lymphocytes in primary biliary cirrhosis," Journal of Clinical Investigation, vol. 109, no. 9, pp. 1231-1240, 2002.

[110] A. Lleo, C. L. Bowlus, G. X. Yang et al., "Biliary apotopes and anti-mitochondrial antibodies activate innate immune responses in primary biliary cirrhosis," Hepatology, vol. 52, no. 3, pp. 987-998, 2010.

[111] A. Lleo, C. Selmi, P. Invernizzi et al., "Apotopes and the biliary specificity of primary biliary cirrhosis," Hepatology, vol. 49, no. 3, pp. 871-879, 2009.

[112] G. Rong, R. Zhong, A. Lleo et al., "Epithelial cell specificity and apotope recognition by serum autoantibodies in primary biliary cirrhosis," Hepatology, vol. 54, no. 1, pp. 196-203, 2011.

[113] J. Van de Water, D. Fregeau, P. Davis et al., "Autoantibodies of primary biliary cirrhosis recognize dihydrolipoamide acetyltransferase and inhibit enzyme function," Journal of Immunology, vol. 141, no. 7, pp. 2321-2324, 1988.
[114] G. Nalbandian, J. Van De Water, R. Gish et al., "Is there a serological difference between men and women with primary biliary cirrhosis?" American Journal of Gastroenterology, vol. 94, no. 9, pp. 2482-2486, 1999.

[115] C. Selmi, F. Meda, A. Kasangian et al., "Experimental evidence on the immunopathogenesis of primary biliary cirrhosis," Cellular and Molecular Immunology, vol. 7, no. 1, pp. 1$10,2010$.

[116] R. Bown, M. L. Clark, and D. Doniach, "Primary biliary cirrhosis in brothers," Postgraduate Medical Journal, vol. 51, no. 592, pp. 110-115, 1975.

[117] A. Tanaka, A. T. Borchers, H. Ishibashi, A. A. Ansari, C. L. Keen, and M. E. Gershwin, "Genetic and familial considerations of primary biliary cirrhosis," American Journal of Gastroenterology, vol. 96, no. 1, pp. 8-15, 2001.

[118] K. N. Lazaridis, B. D. Juran, G. M. Boe et al., "Increased prevalence of antimitochondrial antibodies in first-degree relatives of patients with primary biliary cirrhosis," Hepatology, vol. 46, no. 3, pp. 785-792, 2007.

[119] C. Corpechot, Y. Chretien, O. Chazouilleres, and R. Poupon, "Demographic, lifestyle, medical and familial factors associated with primary biliary cirrhosis," Journal of Hepatology, vol. 53, no. 1, pp. 162-169, 2010.

[120] M. E. Gershwin, C. Selmi, H. J. Worman et al., "Risk factors and comorbidities in primary biliary cirrhosis: a controlled interview-based study of 1032 patients," Hepatology, vol. 42, no. 5, pp. 1194-1202, 2005.

[121] A. Parikh-Patel, E. B. Gold, H. Worman, K. E. Krivy, and M. E. Gershwin, "Risk factors for primary biliary cirrhosis in a cohort of patients from the United States," Hepatology, vol. 33, no. 1, pp. 16-21, 2001.

[122] M. I. Prince, S. J. Ducker, and O. F. W. James, "Case-control studies of risk factors for primary biliary cirrhosis in two United Kingdom populations," Gut, vol. 59, no. 4, pp. 508512, 2010.

[123] D. S. Smyk, D. P. Bogdanos, S. Kriese, C. Billinis, A. K. Burroughs, and E. I. Rigopoulou, "Urinary tract infection as a risk factor for autoimmune liver disease: from bench to bedside," Clinical Research in Hepatology and Gastroentrology, vol. 36, no. 2, pp. 110-121, 2012.

[124] F. K. Varyani, J. West, and T. R. Card, "An increased risk of urinary tract infection precedes development of primary biliary cirrhosis," BMC Gastroenterology, vol. 11, article 95, 2011.

[125] M. J. Goo, M. R. Ki, H. R. Lee et al., "Primary biliary cirrhosis, similar to that in human beings, in a male C57BL/6 mouse infected with Helicobacter pylori," European Journal of Gastroenterology \& Hepatology, vol. 20, no. 10, pp. 10451048, 2008.

[126] A. Koutsoumpas, M. Mytilinaiou, D. Polymeros, G. N. Dalekos, and D. P. Bogdanos, "Anti-Helicobacter pylori antibody responses specific for VacA do not trigger primary biliary cirrhosis-specific antimitochondrial antibodies," European Journal of Gastroenterology \& Hepatology, vol. 21, no. 10, p. 1220, 2009.

[127] L. R. Rubel, L. Rabin, L. B. Seeff, H. Licht, and B. A. Cuccherini, "Does primary biliary cirrhosis in men differ from primary biliary cirrhosis in women?" Hepatology, vol. 4, no. 4, pp. 671-677, 1984.

[128] M. R. Lucey, J. M. Neuberger, and R. Williams, "Primary biliary cirrhosis in men,” Gut, vol. 27, no. 11, pp. 1373-1376, 1986.

[129] N. Krasner, P. J. Johnson, B. Portmann, G. Watkinson, R. N. Macsween, and R. Williams, "Hepatocellular carcinoma in 
primary biliary cirrhosis: report of four cases," Gut, vol. 20, no. 3, pp. 255-258, 1979.

[130] W. M. Melia, P.J. Johnson, J. Neuberger, S. Zaman, B. C. Portmann, and R. Williams, "Hepatocellular carcinoma in primary biliary cirrhosis: detection by alpha-fetoprotein estimation," Gastroenterology, vol. 87, no. 3, pp. 660-663, 1984.

[131] C. Selmi, "The X in sex: how autoimmune diseases revolve around sex chromosomes," Best Practice \& Research Clinical Rheumatology, vol. 22, no. 5, pp. 913-922, 2008.

[132] I. Bianchi, A. Lleo, M. E. Gershwin, and P. Invernizzi, "The $\mathrm{X}$ chromosome and immune associated genes," Journal of Autoimmunity, vol. 38, no. 2-3, pp. 187-192, 2012.

[133] P. Invernizzi, M. Miozzo, C. Selmi et al., "X chromosome monosomy: a common mechanism for autoimmune diseases," Journal of Immunology, vol. 175, no. 1, pp. 575-578, 2005.

[134] A. Lleo, P. M. Battezzati, C. Selmi, M. E. Gershwin, and M. Podda, "Is autoimmunity a matter of sex?" Autoimmunity Reviews, vol. 7, no. 8, pp. 626-630, 2008.

[135] Z. Ozbalkan, S. Bagislar, S. Kiraz et al., "Skewed X chromosome inactivation in blood cells of women with scleroderma," Arthritis \& Rheumatism, vol. 52, no. 5, pp. 1564-1570, 2005.

[136] E. Uz, L. S. Loubiere, V. K. Gadi et al., "Skewed X-chromosome inactivation in scleroderma," Clinical Reviews in Allergy and Immunology, vol. 34, no. 3, pp. 352-355, 2008.

[137] T. H. Brix, G. P. Knudsen, M. Kristiansen, K. O. Kyvik, K. H. Orstavik, and L. Hegedus, "High frequency of skewed $\mathrm{X}$-chromosome inactivation in females with autoimmune thyroid disease: a possible explanation for the female predisposition to thyroid autoimmunity," The Journal of Clinical Endocrinology \& Metabolism, vol. 90, no. 11, pp. 5949-5953, 2005.

[138] T. Ozcelik, "X chromosome inactivation and female predisposition to autoimmunity," Clinical Reviews in Allergy and Immunology, vol. 34, no. 3, pp. 348-351, 2008.

[139] M. Miozzo, C. Selmi, B. Gentilin et al., "Preferential X chromosome loss but random inactivation characterize primary biliary cirrhosis," Hepatology, vol. 46, no. 2, pp. 456-462, 2007.

[140] M. M. Mitchell, A. Lleo, L. Zammataro et al., "Epigenetic investigation of variably $\mathrm{X}$ chromosome inactivated genes in monozygotic female twins discordant for primary biliary cirrhosis," Epigenetics, vol. 6, no. 1, pp. 95-102, 2011.

[141] Y. Weinstein, S. Ran, and S. Segal, "Sex-associated differences in the regulation of immune responses controlled by the MHC of the mouse," Journal of Immunology, vol. 132, no. 2, pp. 656-661, 1984.

[142] A. Amadori, R. Zamarchi, G. De Silvestro et al., "Genetic control of the CD4/CD8 T-cell ratio in humans," Nature Medicine, vol. 1, no. 12, pp. 1279-1283, 1995.

[143] A. Bouman, M. Jan Heineman, and M. M. Faas, "Sex hormones and the immune response in humans," Human Reproduction Update, vol. 11, no. 4, pp. 411-423, 2005.

[144] A. V. Rubtsov, K. Rubtsova, J. W. Kappler, and P. Marrack, "Genetic and hormonal factors in female-biased autoimmunity," Autoimmunity Reviews, vol. 9, no. 7, pp. 494-498, 2010.

[145] N. Kanda and K. Tamaki, "Estrogen enhances immunoglobulin production by human PBMCs," Journal of Allergy and Clinical Immunology, vol. 103, no. 2, pp. 282-288, 1999.

[146] N. Kanda, T. Tsuchida, and K. Tamaki, "Estrogen enhancement of anti-double-stranded DNA antibody and immunoglobulin $\mathrm{G}$ production in peripheral blood mononuclear cells from patients with systemic lupus erythematosus," Arthritis \& Rheumatism, vol. 42, no. 2, pp. 328-337, 1999.

[147] N. Kanda, T. Tsuchida, and K. Tamaki, "Testosterone inhibits immunoglobulin production by human peripheral blood mononuclear cells," Clinical and Experimental Immunology, vol. 106, no. 2, pp. 410-415, 1996. 


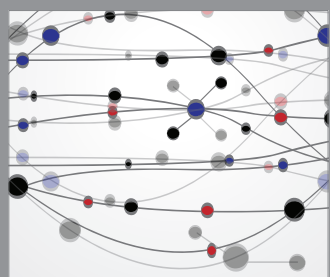

The Scientific World Journal
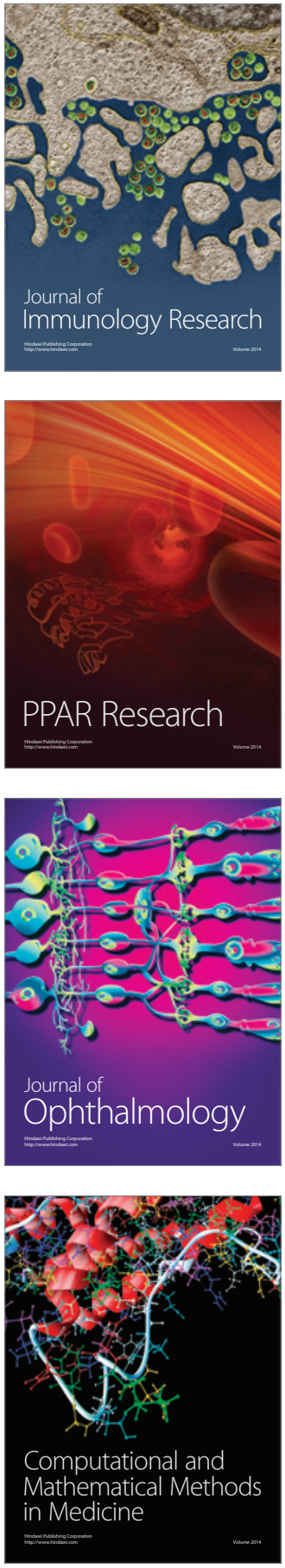

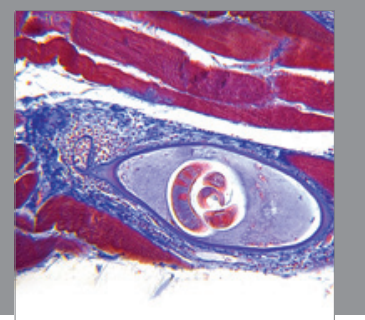

Gastroenterology

Research and Practice
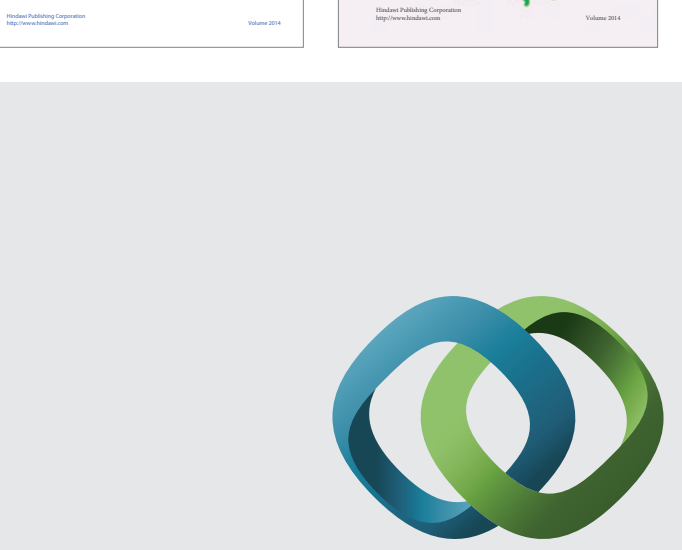

\section{Hindawi}

Submit your manuscripts at

http://www.hindawi.com


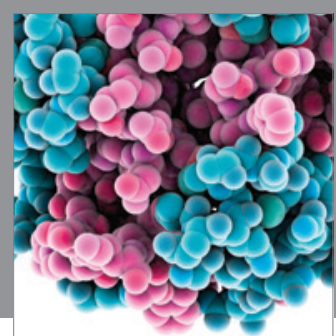

Journal of
Diabetes Research

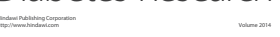

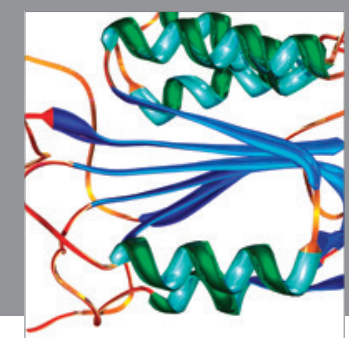

Disease Markers
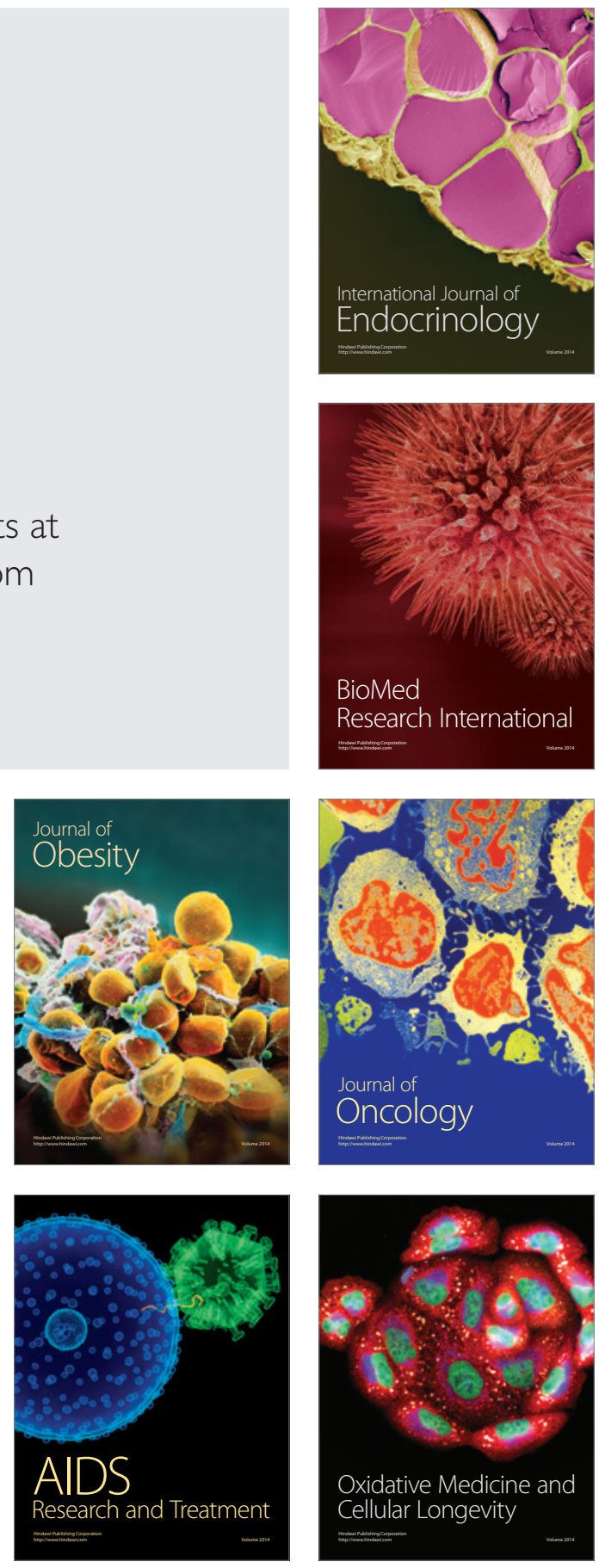